NBER WORKING PAPER SERIES

\title{
APPROPRIABILITY AND THE TIMING OF INNOVATION: EVIDENCE FROM MIT INVENTIONS
}

\author{
Emmanuel Dechenaux \\ Brent Goldfarb \\ Scott A. Shane \\ Marie C. Thursby \\ Working Paper 9735 \\ http://www.nber.org/papers/w9735
NATIONAL BUREAU OF ECONOMIC RESEARCH
1050 Massachusetts Avenue
Cambridge, MA 02138
May 2003

We thank Fritz Foley, Yan Meuniere, Scott Stern, Jerry Thursby, and participants of seminars at Carnegie Mellon, Emory, and Stanford Universities, the NBER Summer Institute and the International Industrial Organization Conference at Northwestern University for useful comments. We are particularly grateful to Lita Nelson of the MIT Technology Licensing Office for providing access to the data and for answering many questions. Thursby gratefully acknowledges the Kauffman Foundation and the National Science Foundation (Awards SES-0094573 and NSF-IGERT 0221600). Both Thursby and Dechenaux thank the Alan and Mildred Peterson Foundation for research support. The views expressed herein are those of the author(s) and do not necessarily reflect the views of the National Bureau of Economic Research.

(C) 2003 by Emmanuel Dechenaux, Brent Goldfarb, Scott A. Shane, and Marie C. Thursby. All rights reserved. Short sections of text, not to exceed two paragraphs, may be quoted without explicit permission provided that full credit, including $\odot$ notice, is given to the source. 
Appropriability and the timing of innovation: Evidence from MIT inventions Emmanuel Dechenaux, Brent Goldfarb, Scott A. Shane, and Marie C. Thursby NBER Working Paper No. 9735

May 2003, Revised July 2007

JEL No. O31,O32

\begin{abstract}
$\underline{\text { ABSTRACT }}$
At least since Arrow (1962), the effects of appropriability on invention have been well studied, but there has been little analysis of the effect of appropriability on the commercialization of existing inventions. Exploiting a database of 805 attempts by private firms to commercialize inventions licensed from MIT between 1980 and 1996, we explore the influence of several appropriability mechanisms on the commercialization and termination of projects to develop products based on university inventions. Our central hypothesis is that the relationship between a licensee's decision to either terminate or commercialize the invention is driven by the current market value of the invention, as well as the option value of delaying its commercialization. We use a competing risks framework that allows for non- parametric heterogeneity and correlated risks. We find that better appropriability in the sense of more effective patent strength and secrecy has a strong negative effect on the hazard of license termination. The effectiveness of learning has a strong positive effect on the hazard of technology commercialization, while lead time has a negative effect.

Emmanuel Dechenaux

Kent State University

Department of Economics

Kent, OH 44242-0001

edechena@kent.edu

Brent Goldfarb

Robert H. Smith School of Business

University of Maryland

4548 Van Munching Hall

College Park, MD 20742

bgoldfarb@rhsmith.umd.edu

Scott A. Shane

Dept. of Economics

Case Western Reserve University

10900 Euclid Ave.

Cleveland, OH 44106

sas46@po.cwru.edu

Marie C. Thursby

College of Management

Georgia Institute of Technology

800 West Peachtree street, NW

Atlanta, GA 30332-0520

and NBER

marie.thursby@mgt.gatech.edu
\end{abstract}




\section{Introduction}

Do strong intellectual property rights enhance the commercialization of new technology? Surprisingly, we do not know the answer to this question (Gallini 2002). Although the role of property rights in innovation has been studied extensively since Arrow (1962) argued that firms under invest in R\&D because they cannot fully appropriate the returns, much of this work focuses on the effect of intellectual property rights, particularly those associated with patents, on inventive activity. Moreover, while there is a rich literature on the determinants of licensing activity (Thursby and Thursby 2007), there has been little analysis of whether licensed inventions are commercialized, or the effects of appropriability mechanisms on these outcomes (Hahn 2003). As firms increasingly rely on externally generated inventions, particularly those invented and patented by universities, this represents an important gap in our understanding (Arora et al. 2001, Santoro and Chakrabarti 2002, Thursby and Thursby 2003).

We examine the effect of various appropriability mechanisms on the commercialization of university inventions by exploring the same population of inventions licensed from the Massachusetts Institute of Technology (MIT) used in Shane's (2002) work on the determinants of licensing. Specifically, we examine the population of 805 attempts by private firms to commercialize patentable inventions licensed from the MIT between 1980 and 1996. For these inventions, we relate appropriability mechanisms to the timing of termination and commercialization decisions.

We view the decision of a licensing firm as an optimal stopping problem under uncertainty (see Dixit and Pindyck 1994). This uncertainty stems from the embryonic nature of university technologies and the difficulty in identifying and protecting associated markets (Thursby and Thursby 2002, Shane 2000). Survey evidence from university technology licensing offices (TLO) shows that the majority of inventions licensed are no more than a lab scale prototype at the time of license (Jensen and Thursby 2001 and Thursby et al. 2001). Thus, for most university inventions, further development is needed

for commercial application. Survey evidence from businesses that license-in university inventions shows that this development is risky: half of all commercialization efforts fail and $47 \%$ of these failures can be attributed to technical reasons (Thursby and Thursby 2003).

Market uncertainty is an additional source of risk for nascent university technologies. Defining market opportunities for early stage inventions is difficult, so much so that many university inventions end up with applications that are not anticipated at the time 
of license (Shane 2000, and Thursby and Thursby 2002). Further, exclusive licenses such as those we consider, do not necessarily prevent competitors from developing substitutes or inventing around a licensed patent.

In this context, we consider the fact that at every point in time the licensee can decide to either commercialize; drop the license; or keep the license but delay commercialization. This gives rise to a real option in commercialization. Moreover, returns may be appropriated using a variety of mechanisms. While some of these are legal, such as patents or trade secrets, others, such as learning or a first mover advantage, are consequences of business strategy (Cohen et al. 2000, Kamien and Schwartz 1972, Levin et al. 1987, and Takalo and Kanniainen 2000). In our theoretical discussion, we argue that different appropriability mechanisms influence the timing of licensees' decisions by affecting either the current market value of commercializing the invention, the option value of keeping the license without commercialization, or both.

Estimation of the hazard rates of termination of the license and commercialization of the invention reveals that legal mechanisms have a strong and negative effect on the hazard of termination. However, with the exception of patent scope, they have only a weak effect on the hazard of commercialization. The reverse is true for appropriability mechanisms based on business strategy, which primarily affect the hazard of commercialization. These results are consistent with our theoretical arguments, under the assumption that most university technologies are embryonic. They are also in line with the observation that when appropriability mechanisms such as patents and secrecy are effective, firms may be able to appropriate returns from the license without commercializing a product.

By showing that several dimensions of appropriability affect the hazards of license termination and invention commercialization, we contribute to the literature on appropriability and innovation. In particular, our results on patent strength contribute to the extensive literature on patents and innovation (for a survey, see Gallini 2002). By treating the decision to commercialize an invention as an optimal stopping problem, we examine patent scope and innovation in a way that incorporates the possibility of termination, which, though quite relevant to embryonic technologies licensed to firms, has been ignored in the literature.

Furthermore, we contribute to the empirical literature on the effectiveness of patents in appropriating the returns from R\&D by directly examining the relationship between patent characteristics and the development of products based on newly invented technologies, rather than relying on perceptions of R\&D personnel responding to surveys (Taylor and Silberston 1973, Mansfield 1986, and Mansfield et al. 1981). 
Our analysis also extends the literature on product development and management. For example, Lilien and Yoon (1990) and Bayus et al. (1997) show that it may be optimal for market pioneers to delay product launch depending on demand characteristics, as well as market competition. Our results on commercialization contribute to this literature by relating the hazard of commercialization to appropriability mechanisms. In this regard, we also contribute to the literature on commercialization strategy. For example, Gans, Hsu and Stern (2003) examine whether innovative startup firms commercialize their innovations independently or by partnering with other firms as a function of patent rights, secrecy, or the litigation environment. Both our theoretical discussion and our empirical results add to this line of inquiry by considering other measures of appropriability and the timing of independent commercialization.

Finally, we contribute to the practice of technology management and strategy by highlighting the fact that the intuitive tradeoff between current market value and option value depends strongly on appropriability conditions. An important implication, validated by the empirical analysis, is that in lines of business where learning is an effective means of appropriating returns, the current market value tends to dominate and inventions are brought to market quickly. By contrast, in lines of business where being a first mover is effective, delays in commercialization may occur because of the option value associated with further product development. Given the increasing reliance of firms on externally-generated inventions, particularly those developed in universities, this information should be useful to managers in technology-intensive industries.

Section 2 presents our theoretical arguments on the relation of appropriability mechanisms to the timing of a licensee's decisions and the hazards of termination and commercialization. The competing risk hazard model used in the empirical analysis is described in Section 3, and details about our data are provided in Section 4. Section 5 presents the main results, as well as a variety of robustness checks. Section 6 concludes.

\section{Appropriability mechanisms, termination and com- mercialization}

In our analysis, the timing of termination and commercialization is determined by the licensee's optimal decisions when faced with market value uncertainty. Hence, it is natural to consider the conditional probability that either event (commercialization and termination) occurs in time $t$ given that no event has occurred before, that is, the hazards 
of commercialization and termination. In the simplest formulation of the problem, given that the firm has not yet commercialized, the value of the license to the firm will be a function

$$
V_{t}\left(\Pi_{t}, b_{t}, c_{t}\right)
$$

where $\Pi_{t}$ is the current expected value to the firm of cumulated profits from commercializing the invention (net of licensing fees) or market value, $b_{t}$ is the benefit from holding the license without commercializing, and $c_{t}$ is the cost of keeping the license for one additional period without commercializing. This cost may include development costs and surely includes the sum of license fees owed to the university, with the exception of royalties based on sales. The market value, $\Pi_{t}$, the other benefits, $b_{t}$, and the value function $V_{t}$ depend on the effectiveness of appropriability mechanisms such as patent strength, scope and other non-patent mechanisms. They also depend on the amount of time the licensee has been able to spend on development, as well as potentially complex aspects of the product life cycle. The expected value of $V_{t}$ may thus be non-monotonic as a function of time.

Importantly, we consider that the value of the license $V_{t}$ may depend on benefits that are derived from keeping the license, but are unrelated to commercialization $\left(b_{t}\right)$. Firms may license patented inventions in order to build "fences" around products they already produce or to increase their bargaining power in obtaining cross licenses, as well as to earn royalty income (Levin et al. 1987, Cohen et al. 2000, and Arora et al. 2007). In fact, university TLO personnel often express concerns over these motives for licensing and report that the contracts they use in exclusive licensing include due diligence requirements as well as complicated payment terms to discourage firms from shelving the technologies licensed (Dechenaux et al. 2007). Keeping the license without commercializing does not necessarily stem from a pure shelving motive. Note that if property rights are weak (e.g., in electronics or mechanical engineering inventions) the licensee might keep a license until critical knowledge is transferred, but then terminate the license and invent around the patent. ${ }^{1}$ Moreover, this implies that a terminated license may not indicate either lack of technology transfer or technology failure (Goldfarb and Henrekson 2003).

In any period, the licensee will choose not to terminate the license as long as $V_{t}$ is greater than zero. Note that $V_{0}>0$ must hold for all licenses in the sample since the firms voluntarily obtained the license from the university. However, the licensee's

\footnotetext{
${ }^{1}$ Katharine $\mathrm{Ku}$, head of the Stanford Office of Technology Licensing has indicated to the authors that not only does this happen, but it is considered fair-play and not at all unethical.
} 
decision regarding commercialization depends on the difference between expected profits

from immediate commercialization and the option option value of delaying (Takalo and Kanniainen 2000).

Our analysis focuses on how changes in appropriability conditions can affect $V_{t}$ and the difference between current market value (cash-flow effect) and the option value of commercialization (option effect). We make a distinction between appropriability mechanisms that require commercialization and those for which rents may be appropriated without commercializing a product. Further, we distinguish between mechanisms that are legal and those related to business strategy. In the next subsections, we discuss these effects. (For a more formal treatment, the reader is referred to the Appendix.)

\subsection{Patent strength, patent scope, and secrecy}

These three appropriability mechanisms pertain to legal means of protecting intellectual property. Based on Mansfield et al.'s (1981) study of patents and imitation costs, it is natural to think of both patent strength and patent scope as raising the cost of imitating the licensed technology. Secrecy should have the same effect. Hence, an increase in the effectiveness of these mechanisms should result in a higher value for the license, via both the market value and the option of holding the license.

Ceteris paribus, we would expect an increase in patent strength, patent scope, or secrecy to reduce the hazard of termination. This logic should apply whether or not the licensee intends to commercialize the technology; that is, the legal mechanisms of appropriating returns may provide as much or more value from preemption or cross licensing as they do from discouraging imitation of a newly developed product (Arora et al. 2007, Arora and Ceccagnoli 2007).

The dependence of the hazard of commercialization on the specific appropriability mechanism is not as straightforward to characterize. Each legal mechanism increases imitation costs and therefore decreases the probability of imitation. This increases both the market and option values since the firm has a longer window to continue development without competition (Kamien and Schwartz 1972 and Takalo and Kanniainen 2000). The increase in market value should increase the hazard of commercialization, while the option effect works against it. We must note that in Matutes et al.'s (1996) model, greater scope decreases an innovating firm's incentives to delay the introduction of applications, while a longer patent leads to increased delays. An earlier result by Reinganum (1982) shows that perfect patent protection accelerates development and thus market introduction. 
Note further, for firms that have licensed the invention to block rivals, the effect of the option value is, indeed, the only relevant effect. This effect may also be relatively more important when secrecy is effective, particularly if the technology is closely related to existing technology used by the licensee. Indeed, letting a rival firm obtain the license may lead to disclosure of important information because license agreements often include the possibility for the licensee to work closely with the inventor (Jensen and Thursby 2001 and Dechenaux et al. 2007).

\subsection{Learning}

Learning allows the licensee to obtain a significant cost advantage in the product market, and thus, make imitation less profitable. This advantage is achieved by decreasing the cost of producing a given level of quality over time and thus, requires early commercialization. For this reason, we argue that when returns are appropriated through learning, the value of the license derives mainly from the current market value, while the option value of delaying commercialization is low.

How the effectiveness of learning affects termination is ambiguous. If greater effectiveness of learning were simply to reduce the option value of holding the license (all other things being equal) we would expect learning to increase termination. However, when learning is effective, the licensee likely derives a cost advantage in the product market, implying a lower probability of successful imitation. The latter effect would decrease the hazard of termination.

In contrast, learning is unlikely to affect the hazard of commercialization unless the licensee intends to commercialize the technology. Therefore, the expected effect of learning on the hazard of commercialization is straightforward. In order to benefit from learning the firm must commercialize, therefore, ceteris paribus, learning is likely to increase the hazard of commercialization.

\subsection{Lead time}

The licensee's lead time, or the amount of time before entry by the first competitor, is likely to be used to appropriate returns differently across inventions. For instance, lead time may be used to establish a brand name, or develop and secure beneficial relationships with large customers. Such efforts would lower the impact of future entry on the first mover's profit. If, however, lead time is used to get a head start on competitors, then its effectiveness depends on the quality of the commercialized product, and thus, the 
amount of time spent on development. Hence, the relationship between lead time, cash flow, and option effects is not straightforward to characterize.

We expect lead time to be important only to those licensees who have licensed the technology with the goal of commercializing it. If lead time is an effective appropriability mechanism simply because exploiting first mover advantage decreases the probability of imitation, then an increase in lead time should reduce the hazard of termination. However, if lead time is an effective appropriability mechanism only when the licensee manages to capture a significant share of the market as the first mover, the development costs could become too high for the licensee to consider it worthwhile to continue.

The effect of lead time on commercialization is also ambiguous. For an invention that is ready for commercialization, then, conditional on no rival having entered yet, the potential first mover advantage should be reflected in the current market value. However, as Lilian and Yoon (1990) argue, a firm developing a new product will benefit from first mover advantage (consumer lock-in, strong bargaining position with suppliers, etc.) only if its product is of sufficiently high quality (see also Bayus et al. 1997 and Benoit 1987). With this added qualification, the first mover advantage for embryonic inventions will be reflected in the option value of the license, but not necessarily in the market value. Thus for such inventions, the greater the importance of lead time, the lower the hazard of commercialization.

\subsection{Summary of predictions}

Before turning to the empirical analysis of the hazards, we summarize our predictions in Table 1 below. The table relates appropriability measures to the cash-flow and option effects and provides our predictions for the effect of appropriability mechanisms on the hazards of termination and commercialization.

\section{$3 \quad$ Empirical methodology}

Although the cash-flow and option effects taken together have ambiguous effects on the hazards, the panel nature of our data allows us to explore which effect dominates, on average, for our data. We observe a set of MIT inventions, their licensees, and termination and commercialization outcomes. We observe each observation until one of these events, or until it is right censored by the closing of our observation window. Our data reflect the two central competing risks about which we theorize, and we need to 
Table 1: Predictions: Appropriability measures and hazards of termination and commercialization

\begin{tabular}{|l|cc||cc|}
\hline & \multicolumn{3}{|c||}{} & \multicolumn{2}{c}{ Hazard of } \\
& Cash-flow effect & Option Effect & Termination & Commercialization \\
\hline Strength & + & + & - & $+/-^{*}$ \\
\hline Scope & + & + & - & $+/-$ \\
\hline Secrecy & + & + & - & $+/-$ \\
\hline Learning & + & - & $-/+$ & + \\
\hline Lead-time** & & & & + \\
\hline Embryonic & - & + & $+/-$ & + \\
\hline Late stage & + & - & $-/+$ & + \\
\hline
\end{tabular}

${ }^{*} a / b$ indicates that the direction of the overall effect is given by $a$ if the

cash-flow effect dominates the option effect and by $b$ otherwise.

** Depends on the stage of development.

control for the empirical reality of right-censoring. Thus, we adopt a competing risks framework. As we discuss below, we might expect a significant amount of heterogeneity among MIT inventions, which may be difficult to control for. With this in mind, the framework we adopt allows for non-parametric heterogeneity.

Let $T_{f}$ be the duration of a patent that is licensed until first sale and $T_{d}$ be the duration of a license until it is terminated. Define $T=\min \left(T_{f}, T_{d}\right)$ and let $d_{f}$ be an indicator which equals 1 if a patented technology is commercialized (first sale) and 0 otherwise. Let $d_{d}$ be an indicator which equals 1 if a patented technology is terminated and 0 otherwise. Only $\left(T, d_{f}, d_{d}\right)$ are observed. Because $d_{f}$ and $d_{d}$ are observed, exclusion restrictions are not necessary to uncover the latent survival functions, $S\left(k_{f}, k_{d} \mid x\right)$ so long as there is sufficient variation in the vector of regressors $x$ (Abbring and van den Berg 2000, Han and Hausman 1990). Since our data are discrete, we employ a grouped data approach (Han and Hausman 1990). Our model follows McCall (1996).

The probability of a license being terminated conditional on no events occurring through period $k-1$ is:

$$
\operatorname{Pr}\left(T_{d}=k \mid X, T>k-1\right)=1-\exp \left(-\theta_{d} \exp \left(\alpha_{d k}+\beta_{d}^{\prime} x\right)\right)
$$


where $x$ is a set of exogenous (possibly) time-varying regressors. Similarly,

$$
\operatorname{Pr}\left(T_{f}=k \mid X, T>k-1\right)=1-\exp \left(-\theta_{f} \exp \left(\alpha_{f k}+\beta_{f}^{\prime} x\right)\right)
$$

is the probability a first sale associated with a patent occurs conditional on no events occurring through period $k-1$. Period subscripts on $x$ are dropped for readability. Because the theory does not provide us with guidance as to possible exclusion restrictions, we assume that regressors $x$ are identical in both equations.

The joint survivor function conditional on $x$ is:

$$
S\left(k_{s}, k_{d} \mid x\right)=\exp \left(-\theta_{f} \sum_{r=1}^{k_{f}} \exp \left(\alpha_{f k}+\beta_{f}^{\prime} x\right)-\theta_{d} \sum_{r=1}^{k_{d}} \exp \left(\alpha_{d k}+\beta_{d}^{\prime} x\right)\right) .
$$

In what follows, let $\Theta=\left\{\theta_{f}, \theta_{d}\right\} . \quad \alpha_{w k}$ are the baseline parameters and can be interpreted as:

$$
\alpha_{w k}=\log \left(\int_{k-1}^{k} h_{w}(t) d t\right)
$$

where $h_{w}(t)$ is the underlying baseline hazard function and $w \in\{f, d\} . \alpha_{d k}$ and $\alpha_{f k}$ are the respective baseline hazards and are assumed to follow a 3rd order polynomial. A 3rd order polynomial is sufficiently flexible to approximate a baseline hazard function of only five periods. Thus

$$
\alpha_{w k}=\alpha_{0 k}+\alpha_{1 k} k+\alpha_{2 k} k^{2}+\alpha_{3 k} k^{3}
$$

The vectors of parameters $\beta_{w}$ represent the effects of the exogenous variables. Note that all covariates are constant except patent age and year. Define

$$
\begin{aligned}
P_{f}(k) & =S(k-1, k-1 \mid \Theta)-S(k, k-1 \mid \Theta)-0.5[S(k-1, k-1 \mid \Theta)+S(k, k \mid \Theta) \\
& -S(k-1, k \mid \Theta)-S(k, k-1) \mid \Theta], \\
P_{d}(k) & =S(k-1, k-1 \mid \Theta)-S(k-1, k \mid \Theta)-0.5[S(k-1, k-1 \mid \Theta)+S(k, k \mid \Theta) \\
& -S(k-1, k \mid \Theta)-S(k, k-1) \mid \Theta], \\
P_{c}(k) & =S(k-1, k-1 \mid \Theta),
\end{aligned}
$$

where $P_{f}(k)$ is the unconditional probability of first sale by the beginning of period $k$, $P_{d}(k)$ is the unconditional probability of a license being terminated by the beginning of period $k$, and $P_{c}(k)$ is the unconditional probability of neither event occurring through 
the beginning of period $k$. An adjustment, $0.5[S(k-1, k-1 \mid \Theta)+S(k, k \mid \Theta)-S(k-$ $1, k \mid \Theta)-S(k, k-1 \mid \Theta)]$ is made because durations are measured in discrete time.

A key problem with competing risks models identified in the literature is that when the risks are not allowed to correlate, a potential bias may arise. Unobserved determinants of one event (first sale) may be correlated with unobserved determinants of the complementary event (termination) and duration (decision to do neither). We might expect unobserved components, such as quality of the patent and uncertainty associated with success of the technology, to affect both decisions. In our specification, we allow risks to correlate by permitting a three mass-point distribution of location parameter pairs $\theta_{d j}, \theta_{f j}$ where $j=1,2,3$. Each pair occurs with probability $p_{j}$. The six location parameters and two free probabilities are estimated by the data. Thus,

$$
\wp_{w}(k)=\sum_{j=1}^{3} p_{j} P_{w}\left(k \mid \Theta_{j}\right)
$$

The log-likelihood is:

$$
\log L=\sum_{n=1}^{N} \sum_{k=1}^{K_{n}} d_{f k}^{n} \log \wp_{f k}^{n}+d_{d k}^{n} \log \wp_{d k}^{n}+\left(1-d_{f k}^{n}\right)\left(1-d_{d k}^{n}\right) \log \wp_{c k}^{n} .
$$

for each of the $K_{n}$ periods of each of the $N$ attempts.

To identify the model, the baseline hazards $\alpha_{f 0}$ and $\alpha_{d 0}$ are fixed to zero. As there is no constant in the regression, we use deviations from the means in $x$.

\section{Data}

The data used to test the model's predictions were collected from the MIT TLO. Our sample includes all patented inventions made by faculty, staff and students at MIT that were assigned to the Institute between 1980 and 1996 and subsequently licensed exclusively to at least one private sector firm. Our unit of analysis is the license. There were 805 exclusive licenses and 2,875 periods in which licenses were at risk. While it is plausible that licenses are terminated after commercialization, the MIT TLO reports that this is a rare event, and hence this information was not collected. That is, we only observe the first event that occurs. The analysis below predicts the likelihood of the first event.

Our data set is an unbalanced, right censored panel. We have yearly data for each 
attempt from the date of the contractual agreement on the patent until one of three events occurs: it is right censored (in 1996), it is terminated or it is commercialized. The data include the date of termination if the license is terminated and the date of first sale if an invention is commercialized. An observation begins the year that MIT TLO records indicate that a firm first licensed a patent. We code TERMINATION as zero, except in the year (if any) that MIT TLO records indicate that the licensing agreement by the given firm no longer covered the invention or if the patent expired, thereby negating the license. We code FIRSTSALE as zero, except in the year (if any) that MIT TLO records indicate that the first dollar of sales from a product or service embodying the invention was achieved. Our discussions with MIT personnel indicate that record keeping was quite good, hence we are confident our data is an accurate representation of reality.

Table 2 reports the summary statistics. In our data, only 49 of the inventions were commercialized within the first year of the license and the overwhelming majority were never commercialized. Roughly $40 \%$ of the licenses were terminated during the period. ${ }^{2}$

Table 3 reports the unconditional survival rates and the extent of right censoring in the sample. It shows that firms are far more likely to terminate licenses of patents than to successfully commercialize them (323 terminations vs. 197 successes). The table also suggests that uncertainty associated with an innovation is generally resolved in the first 5 years of license because $85 \%$ of licenses either lead to commercialization or are terminated by the end of period 5 , and $90 \%$ of the observed events occur in the first five periods. ${ }^{3}$ The sparseness of this right tail implies that there is little information on which to estimate a baseline hazard. Therefore, we recoded all observations that survived more than five periods as right censored after five periods. The majority (257) are censored during the first four years of the license due to the closing of our observation window in 1996. In addition to the observations that are right-censored after 1996, we censored an additional 74 observations.

\subsection{Measures of appropriability}

As measures of importance of the appropriability mechanisms used in a line of business, we employ four measures from the Yale survey on innovation: patent strength, secrecy, lead time and learning (Levin et al. 1985, Levin et al. 1987). These measures are survey line of business averages. They reflect perceptions of 650 high-level R\&D managers in 130 lines of business about central tendencies of the effectiveness of different mechanisms

\footnotetext{
${ }^{2}$ Note that remaining patent life reflects the mean remaining life of patents at the time of license.

${ }^{3}$ We observe only 2 events after period 10 .
} 
used to appropriate the returns to innovation for process or product $R \& D$ in their lines of business. The managers were asked to rate mechanisms on seven point Likert scales.

To ensure the reliability and validity of their survey, the scholars who conducted the Yale survey pretested their survey with managers from diverse businesses. In addition, to mitigate intra-industry heterogeneity, the respondents were asked to identify major innovations in their industry, and there was not significant variation in responses to this question within industries. Because of their reliability and validity, the measures have been used in several subsequent studies (Cohen and Levinthal 1990, Levin et al., 1987). However, as Griliches (1987) pointed out, the measures for lead time and learning are less objective than those for patent characteristics or secrecy (see "Comments and Discussion" in Levin et al. 1987).

The items are constructed from responses to the following question posed both for production processes and products: "In this line of business, how effective is each of the following means of capturing and protecting the competitive advantages of new or improved products (production processes)". Respondents answered on a seven point Likert scale from "not at all effective" to "very effective".

Patent strength is a measure of the effectiveness of patents as a way to capture and protect competitive advantage in a line of business. It is created from the average response for production processes and products for two means of appropriability: "patents to prevent competitors from duplicating the product (process)" and "patents to secure royalty income". Secrecy is a measure of the effectiveness of keeping key information secret as a way to capture and protect competitive advantage in a line of business. It is created from the average response for production processes and products to "secrecy" as a means of capturing and protecting the competitive advantages of new or improved production processes (products). Lead time is a measure of the effectiveness of being an early mover as a way to capture and protect competitive advantage in a line of business. It is created from the average response for production processes and products to "lead time (being first with a new process [product])". Learning is a measure of the effectiveness of moving ahead of competitors on the learning curve as a way to capture and protect the competitive advantages in a line of business. It is created from the average response for production processes and products to "moving quickly down the learning curve".

Relating our data to the Yale Survey measures of appropriability (described in Section 2) raises an important empirical issue. Because our sample covers the years 1980-1996, while the survey measures appropriability conditions at a particular point in time, we 
must assume that the appropriability differences between lines of business are relatively stable throughout our observation period. There is some evidence that cross-industry differences in such factors in appropriability do not vary significantly over time, as they are a function of the underlying technology in a line of business (Cohen and Levin 1989). Although one might argue that the absolute strength of patents increased during the period, the intellectual property protection afforded by patents for, say, chemical compounds remains very strong relative to that for electronic devices.

We also employ Lerner's (1994) measure of patent scope, which is based upon the number of international patent classifications found on the patent. Lerner (1994) finds that this measure is associated with various measures of economic importance: firm valuation, likelihood of patent litigation, and citations. He argues that it represents broader scope of the monopoly rights covered by the patents. In contrast to the Yale measures, this variable is patent specific.

\subsection{Control variables}

The fact that we do not observe many licenses extending beyond 5 years without a commercialization or termination event does not imply that uncertainty is resolved within five years of issuance of a patent. It is common for licenses to be initiated and survive well into patent life before first sale or termination (Table 4). We measure REMAINING PATENT LIFE as seventeen minus the number of years since the patent was issued, conditional on patent issue at time of license. This variation in the remaining life of a patent at the time of license allows us to separately control for the effects of the age of the license and the remaining time of formal patent protection on the hazards of first sale and termination. The former are measured by the baseline hazard estimates, while the latter are measured by the coefficients on REMAINING PATENT LIFE. Some patents were licensed prior to patent grant. We code the REMAINING PATENT LIFE as 17 for these patents until grant - at which time the clock begins. The patent grant clarifies the property right (Murray and Stern 2007), and might influence decision making. Indeed, we find that the grant has a significant (negative) effect on termination, though none on commercialization. Controlling for this does not influence the other coefficients. As this is tangential to our analysis, it is omitted from these regressions.

We also include TECHNOLOGY CLASS dummies. Following the Hall, Jaffe, and Trajtenberg (2001) classification of patents, we break the patents into five categories: drugs, electronics (including computers and communications), chemicals, mechanical, and other because we might expect different types of technology to take longer to reach 
first sale, as is the case for drugs, which need to first obtain FDA approval.

Reduced form hazard ratios suggest that event patterns in the various categories are distinct. For example, licenses of drug patents tend to survive longer than other types of inventions. That said, these technology class controls are relatively crude, and moreover, the Yale appropriability measures are associated with lines of business, which are, in turn, mapped to the patents via their primary three-digit US patent classes. Hence, there is no variation in the Yale appropriability measures within three-digit patent classes. This leads to concerns that the appropriability measures will proxy for technological heterogeneity. While we cannot eliminate this possibility entirely, we explore it in detail in the next section.

We also include a dummy variable that takes the value 1 if the patent was licensed to a startup, defined as a firm formed to license the particular technology $(33 \%$ of the patents in our sample were licensed to startups). We also include a dummy variable that indicates whether the research that led to the patented invention was funded by industry. (16.8\% of the patents were the result of industry funded research.) Industry funding does not, however, imply that the firm that funded the research necessarily was the licensee. While research sponsors are not generally afforded special licensing rights, in practice we might expect them to be aware of research results earlier than non-sponsors. We are unable to identify cases in which sponsors licensed the output of research they funded because we do not observe the identity of the research sponsors.

\section{Empirical results}

Our results are reported in Table 5. Our unit of observation is a license. In university licensing, several patents may be licensed in a single agreement. If there are many such cases, and they reflect instances in which a single technology is protected through multiple patents, our regressions would overweight these technologies. If such technologies are systematically different than those licensed through single patents, then this pattern would introduce a bias into our analysis. This problem could be mitigated by allowing the error terms to be correlated within each agreement. Unfortunately, we are not aware of a method to implement this strategy and simultaneously control for unobserved heterogeneity. Because we believe that unobserved heterogeneity is a greater problem than the overweighting of technologies represented by multiple patents, we choose to control 
for unobserved heterogeneity in our analyses. ${ }^{4}$

We estimate several regressions, and in so doing investigate the general robustness of our results. In all reported models, we include year dummies to control for technology vintage. Our results are generally robust to the omission of vintage controls.

In model 5a, we report results of a model that includes all of the appropriability measures. We find that PATENT STRENGTH is negatively related to the hazard of license termination. Although the coefficient on PATENT SCOPE is negative, it is not significant at conventional levels. Thus, we find some support for our prediction that appropriability measures directly related to patents will reduce termination hazards. In contrast, we find that PATENT STRENGTH has no measurable effect on the hazard of commercialization, but PATENT SCOPE has a strong, highly significant effect on this hazard. We find no measurable relationship between PATENT STRENGTH and invention commercialization. Recalling Table 1, either the cash-flow and option effects wash each other out, or alternatively, there is no relationship. However, the strong positive relationship between PATENT SCOPE and commercialization hints that the cash-flow effect is dominant. This conclusion is reinforced by the results regarding SECRECY and LEARNING. As predicted by our theory, we find that SECRECY is negatively and significantly related to TERMINATION. We also find that SECRECY is positively and significantly related to COMMERCIALIZATION, which is consistent with the suggestion that cash-flow effects are, on average, dominant. While the point estimate for LEARNING is negative in the termination equation, it is not significant at conventional levels. We precisely measure a positive relationship between LEARNING and the hazard of commercialization, as predicted by our theory. Note that the theory generated ambiguous predictions for two of the three coefficients that empirically we fail to measure with precision (PATENT SCOPE and LEARNING in the termination equation and PATENT STRENGTH in the commercialization equation). We find a positive relationship (at the 10\% level) between LEAD TIME and termination and a negative relationship between this measure and commercialization (at the $5 \%$ level). The combined termination and commercialization results suggest that, for inventions in lines of business in which LEAD TIME is effective, the current market value is low, most likely because of the need for

\footnotetext{
${ }^{4}$ We might also average patent characteristics within a license. However, this would create a problem as large as the one it was intended to solve. Averaging would leave us unable to accommodate the cases in which one of the licensed patents was either commercialized or terminated separately from the rest of the patents under the license agreement, which we observe in a significant number of cases. Moreover, discussions with the director of the MIT TLO indicates that separate termination is a common occurrence and is represented by several anecdotes in the "lay" theory of technology transfer officers about how to think about these data.
} 
further development. As per Table 1, in the case of commercialization, assuming that inventions are embryonic, both the cash flow and option effects reinforce each other.

We explore the robustness of these results in models 5b-5f. In model 5b, we introduce controls for whether the licensee was a startup and whether the research that generated the patent was funded by industry. A log likelihood test rejects the null hypothesis that these four coefficients are jointly zero $(\mathrm{LR}$ statistic $=11.50)$. Both STARTUP and INDUSTRY FUNDED are negatively related to termination (the former result is consistent with findings of Lowe and Ziedonis 2006). Our results remain unchanged except that we no longer measure a relationship between LEAD TIME and termination. Further (unreported) analysis indicates that this is due to the inclusion of the STARTUP control, which suggests that our measured positive relationship between LEAD TIME and termination is the result of underlying negative correlation between LEAD TIME and startups, who tend to license technologies where LEAD TIME is a less important appropriability mechanism. In model 5c, we include 4 broad technology class dummies. When these dummies are included, PATENT STRENGTH and PATENT SCOPE are significantly related to both termination and commercialization. In this model, PATENT SCOPE becomes significant (and negative) at the $10 \%$ level in the termination equation and PATENT STRENGTH becomes positive and significant in the commercialization equation.

It was not possible to estimate a more parsimonious model that simultaneously excluded class, age, and year controls, included a 3-point mass structure, and a cubic form for the baseline hazard. We suspect such a model is not properly identified due to insufficient variation in the data (see Abbring and van den Berg 2000).

With the exception of PATENT SCOPE, our measures of appropriability vary at the level of line of business, as opposed to level of the patent. And while our results are unaffected, or even strengthened by the inclusion of broad technology class dummies, these dummies are only coarse proxies for technology class. Thus, as mentioned earlier, our appropriability measures may pick up unobserved heterogeneity across technology classes and this heterogeneity may drive our results, as opposed to underlying variation in appropriability mechanisms across individual technologies. While controlling nonparametrically for unobserved heterogeneity should alleviate some of these concerns, we conduct three further tests to explore this possibility.

First, if our measures of appropriability are indeed measuring appropriability, their effects should weaken as a patent ages. In model $5 \mathrm{~d}$ we include the interactions of REMAINING PATENT LIFE with both PATENT STRENGTH and PATENT SCOPE. 
We no longer measure direct relationships between PATENT SCOPE and either termination and commercialization. However, the interaction of PATENT SCOPE and REMAINING PATENT LIFE is positive and significant, which suggests that the effect that we found in models $5 \mathrm{a}, 5 \mathrm{~b}$ and $5 \mathrm{c}$ - in which scope is positively related to commercialization - is driven by the younger patents. The main PATENT STRENGTH effect is qualitatively unchanged in both equations. In this model we also find a marginally significant relationship between the interaction of REMAINING PATENT LIFE and PATENT STRENGTH, however this result is not robust (see model 5e).

In model 5e, we include a measure of REMAINING PATENT LIFE as well as that variable's interactions with PATENT STRENGTH and PATENT SCOPE. REMAINING PATENT LIFE, in itself, should have no effect on termination or commercialization unless the patents are strong. This leads us to expect only the interaction terms to be significant. However, REMAINING PATENT LIFE is also a proxy for the age of the technology (as opposed to the age of the license, which is captured by the baseline hazard rate or vintage of the license, which is captured in by the year dummies). Presumably, older technologies have more substitutes which could explain the greater likelihood of termination associated with older patents.

We find only the main (positive) patent strength - commercialization finding remains significant. However, we also find that the coefficient on REMAINING PATENT LIFE interacted with PATENT STRENGTH is negative and significant. This suggests that the main negative relationship found between strength and termination in models $5 \mathrm{a}, 5 \mathrm{~b}$ and $5 \mathrm{c}$ is driven by younger patents. In addition, as in model $5 \mathrm{~d}$, we find the coefficient REMAINING PATENT LIFE interacted with PATENT SCOPE to be significant in the commercialization equation. Thus, these results are consistent with the premise that the appropriability measures are indeed measuring differences in appropriability rather then technological heterogeneity.

Second, we explore the effect of assuming homogeneity. If the appropriability measures are simply picking up unobserved heterogeneity, then these measures should have greater predictive power in a restricted model. In Model $5 \mathrm{f}$, we restrict the risks to be independent, and do not allow unobserved heterogeneity. We strongly reject the hypothesis that there is no unobserved heterogeneity and independent risks (LR statistic $=108.52$ ). While the sign of each coefficient is never reversed, we no longer measure any relationship between PATENT SCOPE or its interaction with REMAINING PATENT LIFE and either termination of commercialization. Indeed, only LEARNING is a significant predictor of commercialization. PATENT STRENGTH, SECRECY, and LEAD 
TIME remain significant predictors of termination. Thus, the data suggest that unobserved heterogeneity is an important characteristic of our data. Failing to control for this obfuscates our central results. To understand the intuition behind this result, consider that, in Model $5 \mathrm{c}$ we found that the hazard of termination decreases if the technology is licensed to a STARTUP, but the hazard of commercialization does not. By contrast, in Model 5f, we find no effect. The sensitivity of the result for STARTUP to controlling for unobserved heterogeneity is what one might expect if start-ups not only differ from well-established firms, but also license inventions that are different from those licensed by established firms. For example, if startups license earlier and riskier inventions, but are more reluctant to terminate the license (because terminating the license agreements might imply terminating the startups as well), then these two effects would tend to cancel out. However, after controlling for this heterogeneity, then Model 5c shows that startup firms are more likely than other licensees to terminate the development projects.

Third, we estimated a model with class controls at a lower level of aggregation. In particular, we estimated a variant of Model 5f, using 24 patent classes as controls and pooling the remainder. The data do not support this specification fully: only for patent classes in which there are a sufficiently high number of observations, can we include patent class dummies and 86 of the 108 patent classes that our data span perfectly predict outcomes because they are represented in the data by one or two licenses. The results of this regression (available upon request) were almost identical to those that appear in Model $5 \mathrm{f}$.

Given the limits of our data, we were unable to estimate a model that simultaneously accounted for unobserved heterogeneity and included patent class controls. Thus, while the results associated with the interaction of remaining patent life and patent strength and scope support the general thrust of our arguments, we do not have sufficient withintechnology-class variation to conclusively rule out the alternative hypothesis that our appropriability measures are picking up other sources of technological heterogeneity, which would reflect an association between appropriability conditions in line of business and termination and commercialization hazards. To the extent that such a correlation might be associated with other unobserved factors, our results must be qualified.

From our robustness analysis, we conclude that the hazard of termination is decreasing in PATENT STRENGTH and SECRECY. The hazard of commercialization is decreasing in LEAD TIME, and increasing in LEARNING, PATENT SCOPE and also PATENT STRENGTH. Based on Table 1, these results are consistent with the cash-flow effect dominating the option effect on average for the technologies in the sample. Further- 
more, our result for lead time is consistent with the assumption that these technologies are embryonic inventions for which further development is required.

To get a sense of the magnitude of the effects, and following the literature of these types of competing risks models, we compute the change in the predicted probabilities of events for the sample. Because the Yale Survey measures are derived from a Likert scale, we look at the effect of a change in one standard deviation from the mean on the predicted probability of events for the sample. Model $5 \mathrm{c}$ predicts both the mean probability of termination and commercialization for the sample to be 0.12 and 0.10 respectively (all numbers are rounded to two digits). If each manager in a line of business associated with each of the inventions had rated the effectiveness of patents one standard deviation higher, the probability of termination for the sample patents would decrease to 0.10 , or $21 \%$ while the probability of commercialization would increase to 0.13 . Similarly, if each manager had rated secrecy one standard deviation higher, the predicted probability of termination decreases $12 \%$ to 0.11 while the predicted probability of commercialization increases $16 \%$ to 0.11 .

We find that each additional international patent class associated with the patent (measured by PATENT SCOPE) decreases the mean predicted probability of termination by $12.5 \%$ to 0.11 and increases the mean predicted probability of commercialization to 0.12 , which represents an increase of $21 \%$. A one standard deviation change in LEAD TIME is associated with a reduction in the commercialization probability to 0.08 , a $17 \%$ decline. A one standard deviation increase in the importance of LEARNING increases the probability of commercialization by $25 \%$ (the mean predicted probability increases to 0.12$)$.

\section{Concluding remarks}

We investigate the role of patents and other appropriability mechanisms in the commercialization of university inventions. An important characteristic of these inventions is that they typically require further development, which is risky for both technical and market reasons. In our theoretical discussion, we view a licensee's decision as an optimal stopping problem in which at every point in time the licensee can decide to either commercialize, drop the license, or keep the license but delay commercialization. This gives rise to a real option in commercialization. How different appropriability mechanisms affect a firm's decisions depends on their impact on the current market value of the license and this real option. 
Our empirical analysis applies a competing risks hazard model which allows for correlated risks and non-parametric unobserved heterogeneity to a dataset of 805 exclusive licenses of MIT patents. We find that the hazard of terminating a license is decreasing in the effectiveness of patent strength and secrecy. One of our most striking results is that, when lead time is important, it appears to be optimal for firms to delay commercialization until the licensee has developed the product. In contrast, we find that patent scope and learning have a positive effect on the hazard of commercialization. These results suggest that, when profiting from embryonic inventions relies heavily on learning, firms should commercialize them as soon as is technically feasible.

A few caveats are in order. First, our analysis does not account for the structure of license agreements. Work by Choi (2001), Jensen and Thursby (2001), Elfenbein (2005), and Dechenaux et al. (2007) has shown that the structure of payment terms can affect development efforts by licensees as well as the inventors themselves. Thus, while considering these effects is beyond our scope, we cannot rule out license structure as a determinant of termination and commercialization. Second, readers are cautioned that MIT is a unique institution and that the results may not generalize to other universities. This suggests the merits of future research based on data from other universities, as well as more fine grained measures of technology characteristics. 


\section{References}

[1] Arora, A., A. Fosfuri, and A. Gambardella (2001). Markets for Technology: The Economics of Innovation and Corporate Strategy. The MIT Press, Cambridge, MA.

[2] Arora, A. and M. Ceccagnoli (2007) "Patent Protection, Complementary Assets, and Firms' Incentives for Technology Licensing," Management Science, Vol. 52, pp. 293-308.

[3] Arora, A., M. Ceccagnoli and W. M. Cohen (2007) "R\&D and the Patent Premium," International Journal of Industrial Organization, Forthcoming.

[4] Arrow, K.J. (1962) "Economic Welfare and the Allocation of Resources for Invention," In R.R. Nelson, editor, The Rate and Direction of Inventive Activity, pp. 609-625. Princeton University Press, Princeton.

[5] Abbring, J.H. and G.J. van den Berg (2000) "The Non-Parametric Identification of the Mixed Proportional Hazards Competing Risks Model," Tinbergen Institute Discussion Papers 00-066/3, Tinbergen Institute.

[6] Bayus, B.L., S. Jain, and A.G. Rao (1997) "Too Little, Too Early: Introduction Timing and New Product Performance in the Personal Digital Assistant Industry," Journal of Marketing Strategy, Vol. 34, pp. 50-63.

[7] Benoit, J. P. (1987) "Innovation and Imitation in a Duopoly," Review of Economic Studies, Vol. 52, pp. 99-106.

[8] Choi, J. P. (2001) "Technology Transfer with Moral Hazard," International Journal of Industrial Organization, Vol. 19, pp. 249-266.

[9] Cohen, W., R. Nelson and J. Walsh (2000) "Protecting Their Intellectual Assets: Appropriability Conditions and Why U.S. Manufacturing Firms Patent (or Not)," NBER Working Paper 7552.

[10] Cohen W. and R. Levin, (1989) "Empirical Studies of Innovation and Market Structure," In R. Schmalensee and R. Willig, eds., Handbook of Industrial Organization, Vol. II. pp. 1059-1107. Elsevier, New York.

[11] Cohen W. and D. Levinthal (1990) "Absorptive Capacity: A New Perspective on Learning and Innovation," Administrative Science Quarterly, Vol. 35, pp. 128-152.

[12] Dechenaux, E., M.C. Thursby and J. Thursby (2007) "Shirking, Sharing Risk, and Shelving: The Role of University License Contracts," mimeo.

[13] Dixit A.K. and R.S. Pindyck (1994). Investment under Uncertainty. Princeton University Press, Princeton. 
[14] Elfenbein, D. (2005) "Contract Structure and Performance of Technology Transfer Agreements," mimeo.

[15] Gallini, N.T. (2002) "The Economics of Patents: Lessons from Recent U.S. Patent Reform," Journal of Economic Perspectives, Vol. 16, pp. 131-154.

[16] Gans, J.S., D.H. Hsu, and S. Stern (2003) "When Does Start-up Innovation Spur the Gale of Creative Destruction?" Rand Journal of Economics, Vol. 33, pp. 571-586.

[17] Goldfarb, B. and M. Henrekson (2003) "Bottom-up versus top-down policies towards the commercialization of university intellectual property," Research Policy, Vol. 32, pp. 639-658.

[18] Hahn, R. W. (2003) "The Economics of Patent Protection: Policy Implications from the Literature," AEI-Brookings Joint Center for Regulatory Studies, mimeo.

[19] Hall, B.H., A.B. Jaffe, and M. Trajtenberg (2001) "The NBER Patent Citation Data File: Lessons, Insights and Methodological Tools," NBER Working Paper 8498.

[20] Han, A. and J. Hausman (1990) "Flexible Parametric Estimation of Duration and Competing Risk Models," Journal of Applied Econometrics, Vol. 5, pp. 1-28.

[21] Jensen, R. and M. Thursby (2001) "Proofs and Prototypes for Sale: The Licensing of University Inventions," American Economic Review, Vol. 91, pp. 240-259.

[22] Kamien, M. and N. Schwartz (1972) “Timing of Innovations Under Rivalry," Econometrica, Vol. 40, pp. 43-60.

[23] Lerner, J. (1994) "The Importance of Patent Scope: An Empirical Analysis," Rand Journal of Economics, Vol. 25, pp. 319-333.

[24] Levin, R., A. Klevorick, R. Nelson, and S. Winter (1987) "Appropriating the returns from industrial research and development," Brookings Papers on Economic Activity, Vol. 3, pp. 783-820.

[25] Lilien, G.L. and E. Yoon (1990) "The Timing of Competitive Market Entry: An Exploratory Study of New Industrial Products," Management Science, Vol. 36, pp. 565-585.

[26] Lowe, R. and A. Ziedonis (2006) "Overoptimism and Performance of Entrepreneurial Firms," Management Science, Vol. 52, pp. 173-186.

[27] Mansfield, E. (1986) "Patents and Innovation: An Empirical Study," Management Science, Vol. 32, pp. 173-181.

[28] Mansfield, E., M. Schwartz, and S. Wagner (1981) "Imitation costs and Patents: An Empirical Study," Economic Journal, Vol. 91, pp. 907-918. 
[29] Matutes C., Regibeau P. and K. Rockett (1996) "Optimal Patent Design and the Diffusion of Innovations," Rand Journal of Economics, Vol. 27, pp. 60-83.

[30] McCall, B. (1996) "Unemployment Insurance Rules, Joblessness, and Part-Time Work," Econometrica, Vol. 64, pp. 647-682.

[31] Murray, F. and S. Stern (2007) "Do Formal Intellectual Property Rights Hinder the Free Flow of Scientific Knowledge? An Empirical Test of the Anti-Commons Hypothesis," Journal of Economic Behavior and Organization, Vol. 63, pp. 648-687.

[32] Reinganum, J.F. (1982) "A Dynamic Game of R and D: Patent Protection and Competitive Behavior," Econometrica, Vol. 50, pp. 671-688.

[33] Santoro, M.D. and A.K. Chakrabarti (2002) "Firm Size and Technology Centrality in Industry-University Interactions," Research Policy, Vol. 31, pp. 1163-1180.

[34] Shane, S. (2000) "Prior Knowledge and the Discovery of Entrepreneurial Opportunities," Organization Science, Vol. 11, pp. 448-469.

[35] Shane, S. (2002) "Selling University Technology: Patterns from MIT," Management Science, Vol. 48, pp. 122-137.

[36] Takalo, T. and V. Kanniainen (2000) "Do Patents Slow Down Technological Progress? Real Options in Patent Research, Patenting, and Market Introduction," International Journal of Industrial Organization, Vol. 18, pp. 1105-1127.

[37] Taylor, C. and Z. Silberston (1973). The Economic Impact of the Patent System. Cambridge University Press, Cambridge.

[38] Thursby, J., R. Jensen, and M.C. Thursby (2001) "Objectives, Characteristics and Outcomes of University Licensing: A Survey of Major U.S. Universities," Journal of Technology Transfer, Vol. 26, pp. 59-72.

[39] Thursby, J., and M.C. Thursby (2002) "Who is Selling the Ivory Tower? Sources of Growth in University Licensing," Management Science, Vol. 48, pp. 90-104.

[40] Thursby, J. and M.C. Thursby (2003) "Buyer and Seller Views of University/Industry Licensing," In Buying In or Selling Out: The Commercialization of the American Research University, Don Stein, editor. Rutgers Press, Forthcoming.

[41] Thursby, J. and M.C. Thursby (2007) "University Licensing," Oxford Review of Economic Policy, Forthcoming. 


\section{Appendix}

\subsection{A simple model termination and commercialization deci- sions}

Consider the problem of a firm that has exclusively licensed a patented invention from MIT. Commercializing in period $t$ yields a stream of expected profits per period whose discounted sum is equal to $\tilde{\Pi}_{t}$. We refer to it as the market value of the license in period $t$. We assume that time is discrete. Before period $t$, from the point of view of the licensee, market value is a random variable with cumulative distribution function $F_{t}\left(\tilde{\Pi}_{t}\right)$. The distribution of $\tilde{\Pi}_{t}$ depends on the time period $t$, but we assume that realizations of market value are independent across time periods. In each period, the licensee learns the current realization $\Pi_{t}$ before making any decision.

In addition to market value, in every period before commercialization, the licensee may earn a benefit $b_{t}$ (rents that are unrelated to commercialization) and must pay a $\operatorname{cost} c_{t}$ (further development cost plus licensing fees) if it keeps the license. For instance, $b_{t}$ will capture the size of the rents the licensee obtains by successfully blocking a rival. It is not excluded that $b_{t}=0$ holds for most of the licenses in our sample.

To characterize the value of the license in a given period $t$, we assume that there exists a period $L$ such that $F_{s}(0)=1$ and $b_{s} \leq c_{s}$ for every $s \geq L$. It is clear that if the firm has neither terminated, nor commercialized by period $L$, it will terminate in that period because the value of the license is equal to zero. We now characterize the value of the license in a given period $t$ by using a standard recursive argument. In period $t=L-1$, the licensee learns the realization of the discounted value of profit $\Pi_{L-1}$ and must then decide whether to commercialize, keep the license or terminate. The licensee will commercialize if $\Pi_{L-1}>\max \left\{b_{L-1}-c_{L-1}, 0\right\}$, it will keep the license without commercializing if $b_{L-1}-c_{L-1} \geq \max \left\{\Pi_{L-1}, 0\right\}$ and terminate otherwise. The value of the license is thus $M_{L-1}=\max \left\{\prod_{L-1}, b_{L-1}-c_{L-1}, 0\right\}$ and its expected value is equal to $E M_{L-1}$. In period $t=L-2$, the licensee must decide whether to terminate the license to earn 0 , commercialize to earn $\Pi_{L-2}$ or to keep the license, but delay commercialization, to earn $b_{L-2}-c_{L-2}+\delta E M_{L-1}$. The value of the license is thus equal to $M_{L-2}=\max \left\{\Pi_{L-2}, b_{L-2}-c_{L-2}+\delta E M_{L-1}, 0\right\}$ and its expected value is equal to $E M_{L-2}$. Continuing in the same fashion, it is clear that in period $t$, the value of the license is equal to

$$
M_{t}=\max \left\{\Pi_{t}, b_{t}-c_{t}+\delta E M_{t+1}, 0\right\}
$$

where $M_{t+1}$ is a defined above.

The benefit $b_{t}$ surely depends on the strength of some of the appropriability mechanisms we consider in the empirical analysis. The term $\delta E M_{t+1}$, which represents the discounted expected value of the license in the next period, depends on appropriability mechanisms as well. Hence, in every period $t<L$, we write the option value of the 
license as follows:

$$
V_{t}\left(\Pi_{t}, b_{t}, c_{t}\right)=\max \left\{\Pi_{t}, b_{t}-c_{t}+\delta E M_{t+1}, 0\right\}
$$

In period $t<L$, the firm's optimal decision may be summarized as follows:

$$
\begin{array}{rc}
\text { Commercialize if } & V_{t}\left(\Pi_{t}, b_{t}, c_{t}\right)=\Pi_{t} \\
\text { Delay if } & V_{t}\left(\Pi_{t}, b_{t}, c_{t}\right)=b_{t}-c_{t}+\delta E M_{t+1} \\
\text { Terminate if } & V_{t}\left(\Pi_{t}, b_{t}, c_{t}\right)=0
\end{array}
$$

Put differently, the licensee will commercialize if

$$
\begin{cases}b_{t}-c_{t}+\delta E M_{t+1}>0 & \text { and } \Pi_{t}>b_{t}-c_{t}+\delta E M_{t+1} \\ \text { or } b_{t}-c_{t}+\delta E M_{t+1} \leq 0 & \text { but } \Pi_{t}>0\end{cases}
$$

and it will terminate if and only if both

$$
b_{t}-c_{t}+\delta E M_{t+1} \leq 0 \text { and } \Pi_{t} \leq 0
$$

Finally, the licensee will delay if and only if

$$
b_{t}-c_{t}+\delta E M_{t+1}>0 \text { but } \Pi_{t}<b_{t}-c_{t}+\delta E M_{t+1}
$$

Thus, if it has neither terminated, nor commercialized by period $t$, the probability that the licensee commercializes in period $t$ is:

$$
h_{t}^{f}= \begin{cases}1-F_{t}\left(b_{t}-c_{t}+\delta E M_{t+1}\right) & \text { if } b_{t}-c_{t}+\delta E M_{t+1}>0 \\ 1-F_{t}(0) & \text { if } b_{t}-c_{t}+\delta E M_{t+1} \leq 0\end{cases}
$$

If it has neither terminated, nor commercialized by period $t$, the probability that the licensee terminates in period $t$ is:

$$
h_{t}^{d}= \begin{cases}0 & \text { if } b_{t}-c_{t}+\delta E M_{t+1}>0 \\ F_{t}(0) & \text { if } b_{t}-c_{t}+\delta E M_{t+1} \leq 0\end{cases}
$$

If the value of delaying, $b_{t}-c_{t}+\delta E M_{t+1}$, is strictly positive, the firm does not terminate since keeping the license is more profitable than terminating it. In this case, even if profits from commercializing in period $t$ are low, the firm recognizes that the license may have sufficient value in the future to justify paying licensing fees. If the license has no value in the future unless commercialized immediately, $b_{t}-c_{t}+\delta E M_{t+1} \leq 0$, then the firm will commercialize in the current period as long as it does not make an overall loss. Otherwise it will terminate. An interesting aspect of the commercialization decision is that other things constant, a high value of $b_{t}-c_{t}+\delta E M_{t+1}$ will lead to a lower probability of commercialization. 


\subsection{Cash-flow and option effect}

Our econometric model uses industry-level measures of the effectiveness of various appropriability mechanisms to estimate the hazards of termination and commercialization. In the text, we discuss the relationship between appropriability mechanisms and the hazards of termination and commercialization in terms of cash-flow and option effects. We define theses two effects below.

Note that, other things constant, the conditional probability of commercialization increases if $F_{t}$ decreases for a given $\Pi_{t}$; that is, if the distribution of the market value assigns a greater probability to higher realizations. This is similar to what Takalo and Kanniainen (2000) call the cash flow effect in their model. However, other things constant, the probability of commercialization decreases as $b_{t}-c_{t}+\delta E M_{t+1}$ increases. This is similar to the option effect in Takalo and Kanniainen and we refer to it as such.

The conditional probability of termination in period $t$ also depends on the cash flow and the option effects. By contrast to commercialization, it is easy to see that the two effects reinforce each other and contribute to decreasing the hazard of termination. 
Figure 1: Unconditional event hazards by period

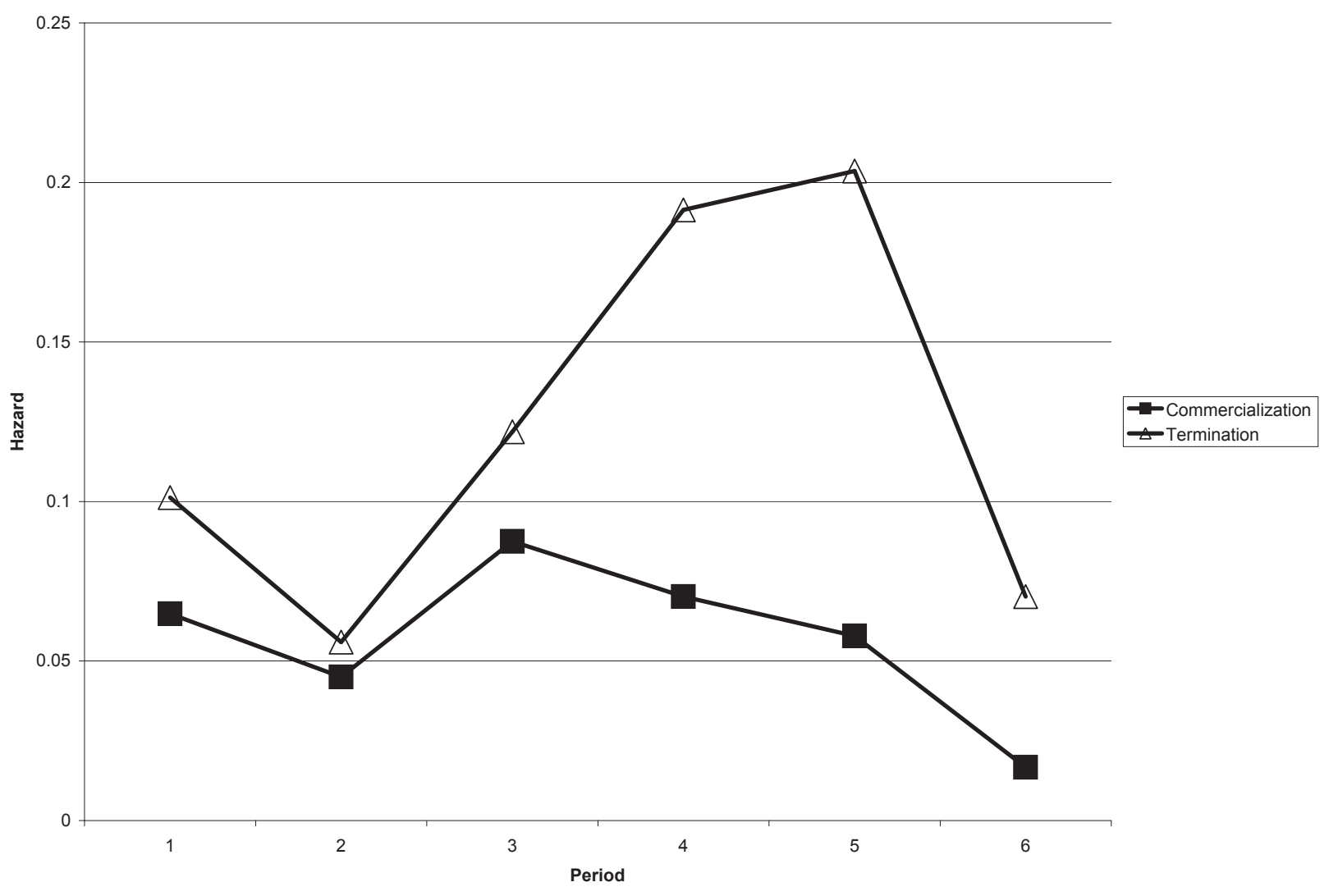


Table 2: Descriptive Statistics

\begin{tabular}{lcccc}
\hline \hline Variable & Mean & Std. Dev. & Min. & Max. \\
\hline Lead Time & 5.369 & 0.506 & 4 & 6.13 \\
Secrecy & 3.923 & 0.406 & 3 & 4.88 \\
Learning & 5.003 & 0.435 & 4 & 5.75 \\
Patent Strength & 4.108 & 0.747 & 1.75 & 5.32 \\
Patent Scope & 1.339 & 0.639 & 1 & 6 \\
Start-up & 0.327 & 0.469 & 0 & 1 \\
Industry Funded & 0.168 & 0.374 & 0 & 1 \\
Drug Patent & 0.216 & 0.412 & 0 & 1 \\
Chemical Patent & 0.311 & 0.463 & 0 & 1 \\
Electric Patent & 0.265 & 0.441 & 0 & 1 \\
Mechanical Patent & 0.032 & 0.177 & 0 & 1 \\
Other Technology & 0.176 & 0.381 & 0 & 1 \\
Remaining Patent Life (17- years since grant) & 12.85 & 3.54 & 1 & 17 \\
Remaining Patent Life * Pat. Strength & 21.29 & 14.76 & 2.73 & 79.80 \\
Remaining Patent Life * Pat. Scope & 6.91 & 6.17 & 1 & 60 \\
\multicolumn{2}{c}{ N } & \multicolumn{3}{c}{805} \\
\hline \hline
\end{tabular}

Table 3: Termination, commercialization and right censoring by age of license

\begin{tabular}{ccccc}
\hline Age of License & Termination & Commercialization & Right Censored & Total \\
\hline 1 & 74 & 49 & 79 & 805 \\
2 & 32 & 26 & 48 & 604 \\
3 & 54 & 40 & 98 & 497 \\
4 & 49 & 20 & 35 & 305 \\
5 & 34 & 11 & 34 & 201 \\
6 & 8 & 2 & 10 & 122 \\
7 & 10 & 6 & 11 & 103 \\
8 & 6 & 2 & 9 & 76 \\
9 & 0 & 11 & 8 & 59 \\
10 & 1 & 1 & 15 & 39 \\
11 & 1 & 0 & 7 & 24 \\
12 & 0 & 0 & 2 & 15 \\
13 & 0 & 0 & 8 & 13 \\
14 & 0 & 0 & 2 & 6 \\
15 & 0 & 0 & 2 & 4 \\
16 & 0 & 168 & 2 & 2 \\
Total & 269 & & 370 & 2875 \\
\hline
\end{tabular}


Table 4: Termination, commercialization and right censoring by patent age

\begin{tabular}{ccccc}
\hline Remaining Patent Life & Termination & First Sale & Right Censored & Total \\
\hline 17 & 38 & 9 & 2 & 48 \\
16 & 38 & 25 & 49 & 112 \\
15 & 31 & 15 & 30 & 76 \\
14 & 24 & 14 & 36 & 74 \\
13 & 37 & 21 & 28 & 85 \\
12 & 20 & 8 & 40 & 68 \\
11 & 12 & 14 & 26 & 52 \\
10 & 15 & 16 & 38 & 69 \\
9 & 13 & 14 & 25 & 52 \\
8 & 11 & 12 & 21 & 44 \\
7 & 12 & 5 & 19 & 36 \\
6 & 7 & 7 & 5 & 19 \\
5 & 8 & 5 & 4 & 17 \\
4 & 3 & 0 & 9 & 12 \\
3 & 0 & 1 & 7 & 8 \\
2 & 0 & 2 & 15 & 17 \\
1 & 0 & 0 & 16 & 16 \\
Total & 269 & 168 & 370 & 805 \\
\hline
\end{tabular}




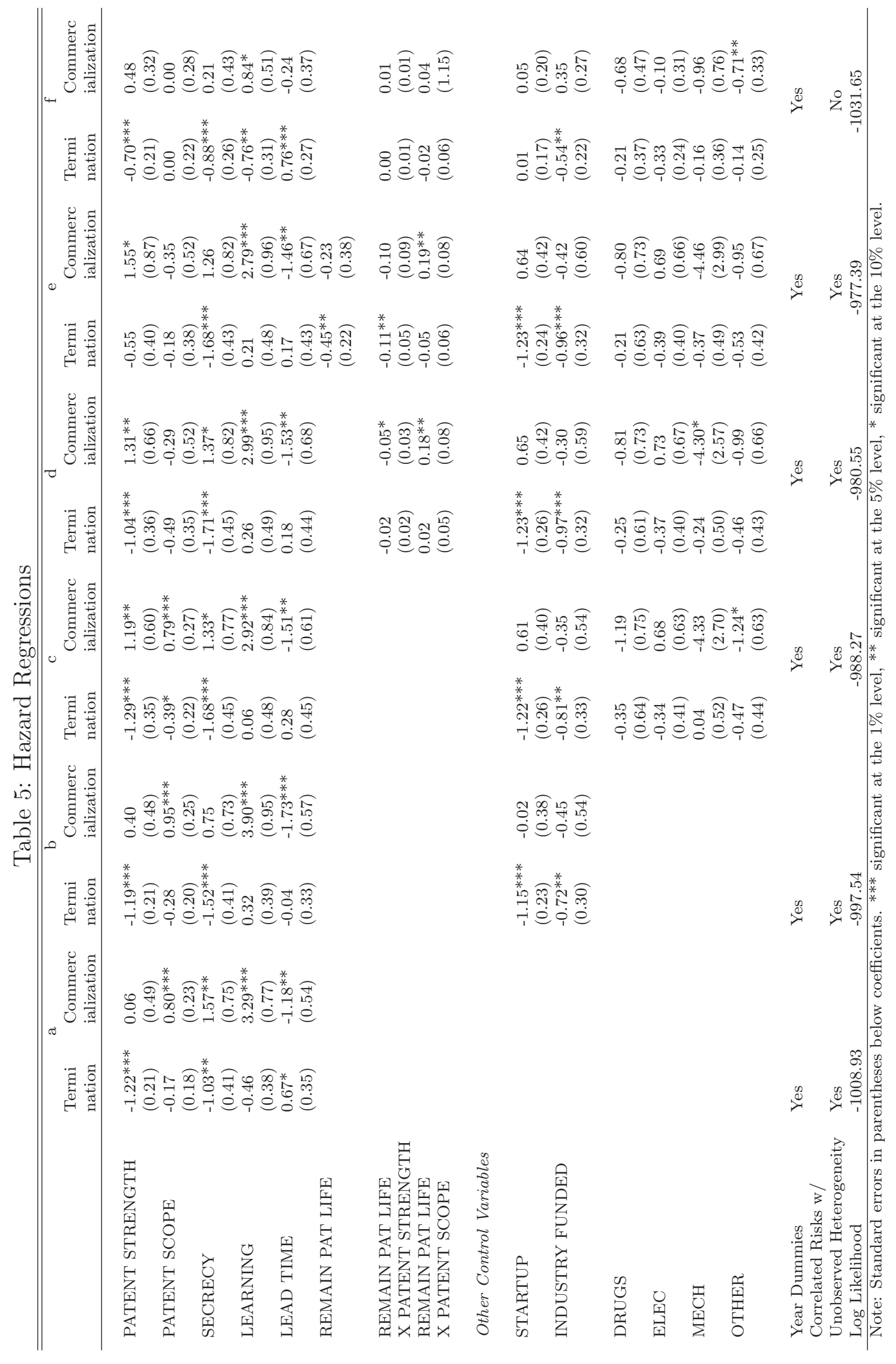

